\title{
Radiochronological Methods as Tools to Study Environmental Pollution
}

\author{
H.N. Erten
}

\begin{abstract}
The study of the environmental impact of natural and anthropogenic events forms the essence of environmental pollution considerations. The nature of the polluting species as well as their time distributions are of primary importance with respect to identifying the polluting sources. Sediments are the most frequently used materials in such studies. Sediments act as the ecological memories of the environments of their formation. Besides classical chronological methods, radiochronological methods developed recently gave a big impetus to environmental pollution studies. One of the key radioisotopic technique is to utilize ${ }^{210} \mathrm{~Pb}$, a product of the ${ }^{235} \mathrm{U}$ radioactive series to date the last 200 years of the sediments. A number of supporting indicators are also utilized. One of them being anthropogenic ${ }^{137} \mathrm{Cs}$ which is used as a time-marker. Large amounts of ${ }^{137} \mathrm{Cs}$ radioactivity was released to the environment during 1954-1963, in time of the most intense atmospheric nuclear arms testing and again in 1986 during the Chernobyl nuclear accident. These intense ${ }^{137} \mathrm{Cs}$ activities form time-markers throughout sediment cores corresponding to their release years. During our studies extending over several years we have used radiochronological methods in dating several sediment cores from Zurich and Constance Lakes in Switzerland from east coast of Spain, Sea of Marmara, from the Black Sea region, Southern coast of Turkey and from North Cyprus. The distribution of several elemental concentrations of importance in pollution considerations along sediment cores were also determined. These studies allowes proposing time frames to pollution events and help inqueries in tracing possible sources of pollution.
\end{abstract}

Keywords Environment · Pollution · Radiochronology

\footnotetext{
H.N. Erten $(\bowtie)$

Department of Chemistry, Bilkent University, 06800 Ankara, Turkey

e-mail: erten@fen.bilkent.edu.tr
} 


\section{Introduction}

The formation of our world and its age has been a curiosity of mankind since ancient times. With the discovery of radioactivity in 1896 the age of the world has been accurately determined using radioisotopic techniques as $4.5 \times 10^{9}$ years. The natural radioactive series of ${ }^{238} \mathrm{U},{ }^{235} \mathrm{U}$ and ${ }^{232} \mathrm{Th}$ and their decay products as well as cosmic ray produced radionuclides have been used for accurate dating of archeological artifacts. These techniques were also useful in establishing a time frame for the impact of natural and anthropogenic activities on the environment. During overground nuclear weapons testing significant amounts of radioisotopes were emitted to the atmoshere. These kinds of activities were most intense in the years 1953-1954 and 1963-1964. Also big nuclear accidents such as Chernobyl in 1986 led to the sharp increases in radioactivities of the various environmental samples. Because of its high fission yield and long half-life the radioisotope ${ }^{137} \mathrm{Cs}$ has been used as a convinient time marker.

Radiochronological dating of sediments from various acquatic environments combined with the measurement of of their chemical profiles allow the study of the impact of natural and cultural events on the surrounding environment. The radionuclide ${ }^{210} \mathrm{~Pb}\left(t_{1 / 2}=22.3 \mathrm{y}\right)$, a member of the natural radioactive decay series of ${ }^{238} \mathrm{U}$, provide a reliable possibility of dating sediments over the last 200 years [1]. This technique has since seen further refined and very widely used by many researchers [2-11]. This method of dating, requires the complete recovery of the topmost sediment layers. ${ }^{7} \mathrm{Be}\left(t_{1 / 2}=53.3 \mathrm{~d}\right)$ a cosmic ray produced nuclide is expected to be present only in the uppermost sediment layers due to its short half-life. The presence of ${ }^{7} \mathrm{Be}$ in the sediments thus ensures complete core recovery.

We have used the above mentioned radioisotopic methods over the years for the dating of sediments from Lakes Zurich and Constance, the sea of Marmara, southern Turkey, eastern Spain, the Black Sea region and northern Cyprus [5-11].

Elemental distributions along the sediment samples were determined using spectrocopic techniques such as XRF, AA. Utilizing the measurements together with the dating results allowed the determination of the time of pollution and their possible sources.

\section{Dating Methods}

\section{$2.1{ }^{210} \mathrm{~Pb}$ Method}

The commonly used radioisotope for dating sediments, ${ }^{210} \mathrm{~Pb}$, is a member of the natural radioactive series ${ }^{238} \mathrm{U}\left(t_{1 / 2}=4.4 \times 10^{9} \mathrm{y}\right) .{ }^{210} \mathrm{~Pb}$ is incorporated into the sediments through the following processes. The noble gas nuclide ${ }^{222} \mathrm{Rn}$ $\left(t_{1 / 2}=3.82 \mathrm{~d}\right)$, a member of the ${ }^{238} \mathrm{U}$ decay chain, diffuses out of the earth's crust and is emmitted to the atmosphere. Radon gas decays completely while in the atmoshere leading to decay products such as ${ }^{210} \mathrm{~Pb} .{ }^{210} \mathrm{~Pb}$ radioisotopes returns 
to land and water surfaces with a constant flux as a result of wet and dry precipitation. In water marine environment ${ }^{210} \mathrm{~Pb}$ is scavenged by suspended particulate matter and accumulates in the sediments. Following the activity of ${ }^{210} \mathrm{~Pb}$ across sediment cores leads to the determination of sedimentation rates and hance dating of the sediment cores over a time scale of 200 years.

\section{$2.2{ }^{137}$ Cs Method}

As a result of extensive nuclear weapons test (1953-1964) and nuclear accidents (Chernobyl 1986) the distribution pattern of fission product ${ }^{137} \mathrm{Cs}$ exhits peaks corresponding to these dates across sediment cores. The positions of these time marker peaks in the sediments all calculations of sedimentation rates. This complementary dating method may be used together with ${ }^{210} \mathrm{~Pb}$ dating.

\section{$2.3{ }^{7}$ Be Method}

Cosmic ray produced radionuclibe ${ }^{7} \mathrm{Be}\left(t_{1 / 2}=53.3 \mathrm{~d}\right)$ is incorporated into the sediments via the same mechanisms as ${ }^{210} \mathrm{~Pb}$ and ${ }^{137} \mathrm{Cs}$. Because of its short half-life however; the radioactivity of ${ }^{7} \mathrm{Be}$ can only be detected in the uppermost layers of sediments. Measurement of ${ }^{7} \mathrm{Be}$ in sediments thus ensures that no loss occurs in the upper parts of sediment cores during the sampling process. Any such loss leads to serious errors in sedimentation rates and thus corresponding dates.

\section{Experimental}

Sediment cores were recovered using either a gravity corer or a box corer. The cores were immediately sampled in $0.5,1$ and $2 \mathrm{~cm}$ intervals after recovery. Part of the core sections were used for textural, mineralogical and chemical studies. ${ }^{210} \mathrm{~Pb}$ was determined through its daughter ${ }^{210} \mathrm{Po}\left(t_{1 / 2}=138.4 \mathrm{~d}\right)$ in radioactive equilibrium with its parent. Polonium was distilled from the sediment at $600^{\circ} \mathrm{C}$ and was converted to the chloride form by several evaporations with $\mathrm{HCl}$. It was taken in a $0.5 \mathrm{M} \mathrm{HCl}$ solution. $\mathrm{SO}_{2}$ gas was bubbled through the solution for 3 minutes at $93^{\circ} \mathrm{C}$. Polonium was self-deposited on a silver disc which was suspended in the hot solution.

One side of the disc was coated with RUTEX, liquid rubber, ensuring deposition on one side only. The overall chemical yield was $90 \%$ as determined by the ${ }^{208} \mathrm{~Pb}$ tracer. Alpha activities were determined using surface-barrier $\alpha$-detectors. The ${ }^{210} \mathrm{Po}$ activities were converted into ${ }^{210} \mathrm{~Pb}$ activities using standard growth and decay equations. In some cases ${ }^{210} \mathrm{~Pb}$ was determined directly by $\gamma$-rayspectrometry via the $46.5 \mathrm{keV}$ line using a hyperpure Ge detector with $92 \mathrm{~cm}^{2}$ active area. The ${ }^{137} \mathrm{Cs}$ and ${ }^{7} \mathrm{Be}$ activities were determined by $\gamma$-ray spectroscopy using a well-type $\mathrm{Ge}(\mathrm{Li})$ detector. 


\section{Results and Discussion}

Sedimantation rates obtained by the above mentioned methods from various regions are summarised in Table 1. The sedimentation rates obtained by three different methods in the dating of Lake Zurich sediments agree quite well with each other. Annual varves were not observed in the sediment samples from other regions. Sediment traps were used in Lake Constance and the rates obtained agree with those from ${ }^{210} \mathrm{~Pb}$ and ${ }^{137} \mathrm{Cs}$ methods. The sedimentation rates at different regions of the Mediterranean and Black Sea given in Table 1 are considerably higher than those from the lakes.

This probably arises due to the fact that the sediment cores were recovered very near the shores. Table 2 gives the distribution of trace elements across sediment cores of Lake Zurich sediments [12].

The trace element levels is seen to be low and somewhat constant before industrialization and gradually reaching maximum values with the beginning of industrialization. It is further observed that due to strict controls the trace element levels start to decrease after 1980. We analyzed the distribution of various trace elements throughout the sediment cores of the sea of Marmara using ICP-AES.

Figure 1 shows the distribution of some of these trace element along the sediment depth.

The elements $\mathrm{Zn}, \mathrm{Cu}, \mathrm{P}$ and possibly $\mathrm{Pb}$ show near surface enrichment corresponding to the last 200 years as found by ${ }^{210} \mathrm{~Pb}$ dating. Since no significant changes were observed in organic and inorganic contents in the sediment cores;enrichment by natural causes can be ruled out. This suggests anthropogenic causes for the observed increases. Towards the end of the eighteenth century, great changes were introduced in the Ottoman Army and Navy. New foundries, armament works, and shipyards were being constructed in and around İstanbul. These activities may be responsible for the enrichment of the above mentioned metallic elements in the sediment cores.

Table 1 Summary of sedimentation rates obtained in our studies at various regions, using different dating methods

\begin{tabular}{lllll}
\hline & \multicolumn{2}{l}{ Mass sedimentation rate $\left(\mathrm{g} \cdot \mathrm{cm}^{2} \cdot \mathrm{y}^{-1}\right)$} & & \\
\cline { 2 - 5 } Sediment core & ${ }^{210} \mathrm{~Pb}$ method & ${ }^{137} \mathrm{Cs}$ time marker & Varve counting & Sediment traps \\
\hline Lake Zurich & $0.073 \pm 0.015$ & $0.07 \pm 0.01$ & $0.07 \pm 0.02$ & - \\
Lake constance & $0.11 \pm 0.02$ & $0.09 \pm 0.01$ & - & $0.14 \pm 0.09$ \\
Sea of Marmara & $0.087 \pm 0.012$ & - & - & - \\
Southern Turkey & $0.083 \pm 0.013$ & - & - & - \\
East Spain & $0.21 \pm 0.02$ & $0.13 \pm 0.02$ & & \\
North Cyprus & $0.17 \pm 0.03$ & $0.19 \pm 0.02$ & & \\
Black sea & $0.22 \pm 0.02$ & $0.17 \pm 0.3$ & & \\
\hline
\end{tabular}


Table 2 Distributions of trace elements across sediment cores from Lake Zurich [12]

\begin{tabular}{|c|c|c|c|c|c|c|}
\hline Sediment depth $(\mathrm{cm})$ & Calender year & $\mathrm{Cu}(\mathrm{ug} / \mathrm{g})$ & $\mathrm{Zn}$ (ug/g) & $\mathrm{Pb}$ (ug/g) & $\mathrm{Cd}(\mathrm{ug} / \mathrm{g})$ & $\mathrm{Hg}(\mathrm{ug} / \mathrm{g})$ \\
\hline 0.3 & 1989 & 48 & 224 & 69 & 1.1 & \\
\hline 0.6 & 1988 & 45 & 235 & 68 & 1.0 & \\
\hline 0.9 & 1987 & 42 & 182 & 57 & 0.75 & \\
\hline 1.5 & 1985 & 47 & 218 & 72 & 1.0 & \\
\hline 1.8 & 1984 & 38 & 197 & 62 & 0.8 & \\
\hline 2.4 & 1982 & 44 & 258 & 86 & 1.0 & \\
\hline 3.6 & 1978 & 49 & 259 & 108 & 1.5 & \\
\hline 3.9 & 1977 & 37 & 232 & 97 & 1.7 & 0.3 \\
\hline 4.5 & 1975 & 46 & 273 & 102 & 2.5 & \\
\hline 5.1 & 1973 & 37 & 300 & 105 & 2.5 & 0.4 \\
\hline 5.4 & 1972 & 46 & 308 & 109 & 2.4 & \\
\hline 5.7 & 1971 & 55 & 375 & 130 & 3.2 & \\
\hline 6.2 & 1969 & 55 & 475 & 137 & 4.0 & 0.7 \\
\hline 6.5 & 1968 & 51 & 398 & 116 & 2.6 & \\
\hline 6.8 & 1967 & 52 & 300 & 107 & 6.5 & \\
\hline 7.4 & 1965 & 61 & 675 & 144 & 6.25 & 0.7 \\
\hline 8.2 & 1962 & 78 & 587 & 104 & 13.4 & \\
\hline 8.6 & 1960 & 67 & 375 & 125 & nd & \\
\hline 9.5 & 1957 & 67 & 476 & 116 & 19.1 & \\
\hline 10.1 & 1955 & 65 & 350 & 150 & 6.2 & 1 \\
\hline 10.7 & 1953 & 56 & 429 & 106 & 10.9 & \\
\hline 11.5 & 1950 & 65 & 170 & 77 & 2.4 & 0.6 \\
\hline 11.8 & 1949 & 56 & 347 & 134 & 5.4 & \\
\hline 13.1 & 1945 & 55 & 250 & 120 & 4.5 & 0.7 \\
\hline 15.0 & 1936 & 53 & 270 & 111 & 4.7 & \\
\hline 15.3 & 1935 & 55 & 375 & 142 & 4.5 & \\
\hline 17.5 & 1930 & & 202 & 130 & 2.0 & \\
\hline 19.5 & 1925 & 47 & 167 & 105 & 1.2 & 0.5 \\
\hline 20.3 & 1921 & 47 & 205 & 138 & 1.3 & \\
\hline 20.6 & 1920 & 57 & 202 & 115 & 1.7 & \\
\hline 22.3 & 1918 & 62 & 165 & 122 & 1.0 & 0.6 \\
\hline 24.5 & 1910 & 67 & 150 & 112 & 1.0 & \\
\hline 27.5 & 1902 & 65 & 150 & 112 & 1.0 & 0.5 \\
\hline 28.0 & 1900 & 77 & 117 & 112 & 1.0 & \\
\hline 29.7 & 1896 & 57 & 82 & 115 & 0.5 & 0.7 \\
\hline 32.5 & 1886 & 32 & 60 & 17 & 0.2 & \\
\hline 40.5 & 1839 & 27 & 55 & 40 & 0.2 & 0.4 \\
\hline 47.0 & 1819 & 20 & 55 & 12 & 0.2 & \\
\hline 52.5 & 1801 & 22 & 50 & 10 & 0.2 & \\
\hline
\end{tabular}

Another interesting example of the environmental impact on sediments was found in the Black Seas Samples. The distribution of some trace elements determined by XRF along the Black Sea sediments is shown in Fig. 2.

It is observed that at about $20 \mathrm{~cm}$ depth there is a noticable increase in these elemental concentrations. This depth corresponds to about 120 years as determined by radiochronology. Examining different anthropogenic factors causing the increase it was noticed that the Creamian war (1854-1856) with intense sea and land fights 
Fig. 1 Distrubition of some trace elements along sediment depth of sea of marmara sediments
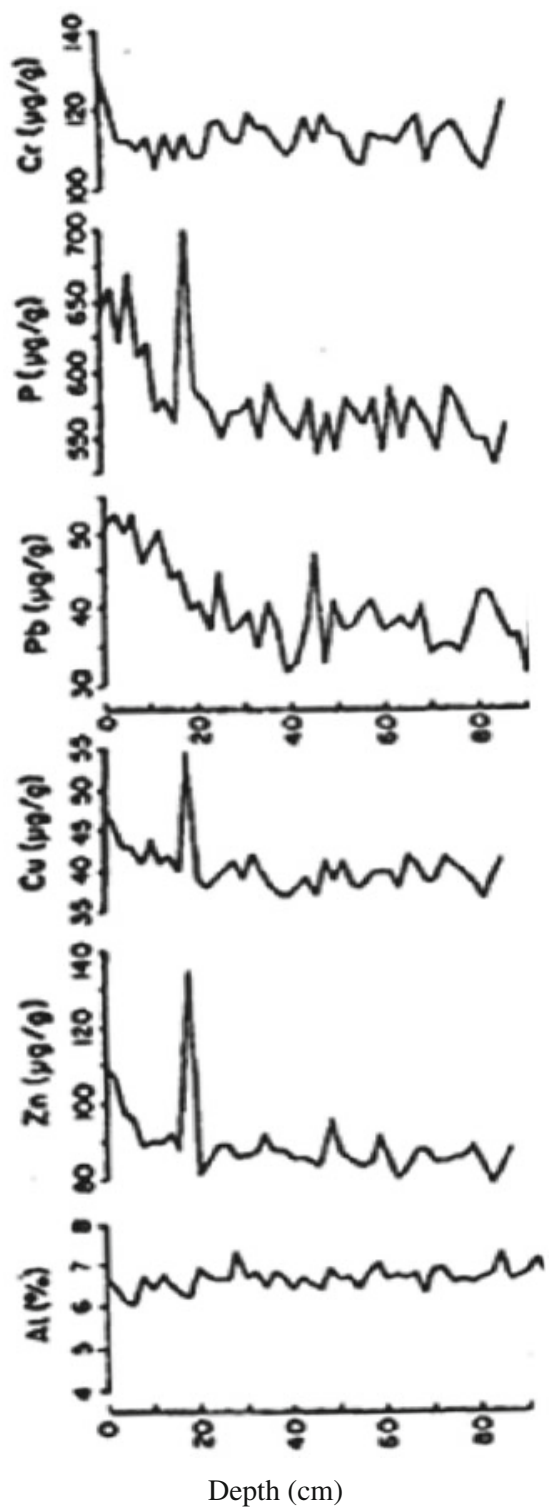

took place during this time. Thus suggesting a possible cause of the observed increases.

The trace element distribution in the sediment cores from southern Turkey determined by XRF spectroscopy is shown in Fig. 3. The increase in the elemental concentrations at $11 \mathrm{~cm}$ depth may be attributed to the industrialization activities in this region. The trace element distrubitions across the sediment depth in the sediment samples from North Cyprus are shown in Fig. 4. 


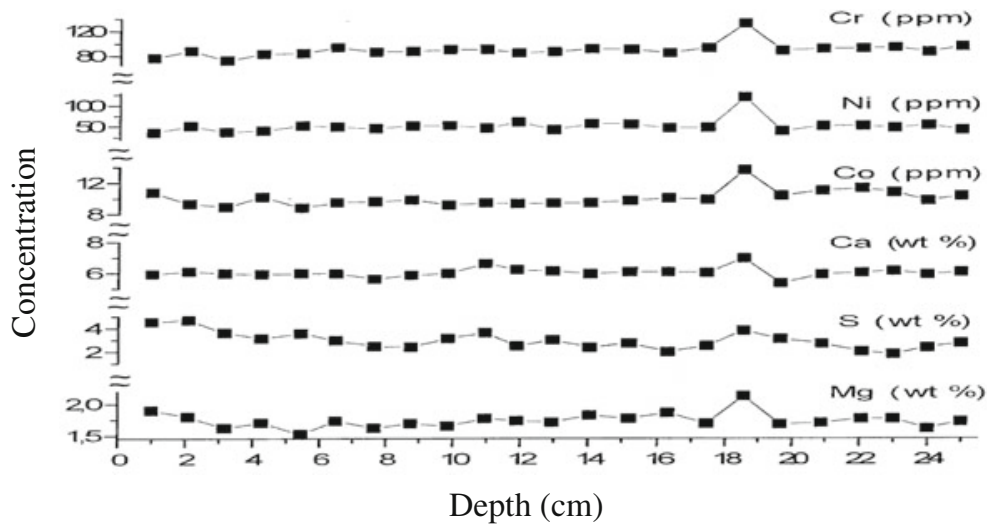

Fig. 2 The distribution of $\mathrm{Ni}, \mathrm{Co}, \mathrm{Cr}, \mathrm{Ca}, \mathrm{Mg}$ and $\mathrm{S}$ determined by $\mathrm{XRF}$, along the Black sea sediments

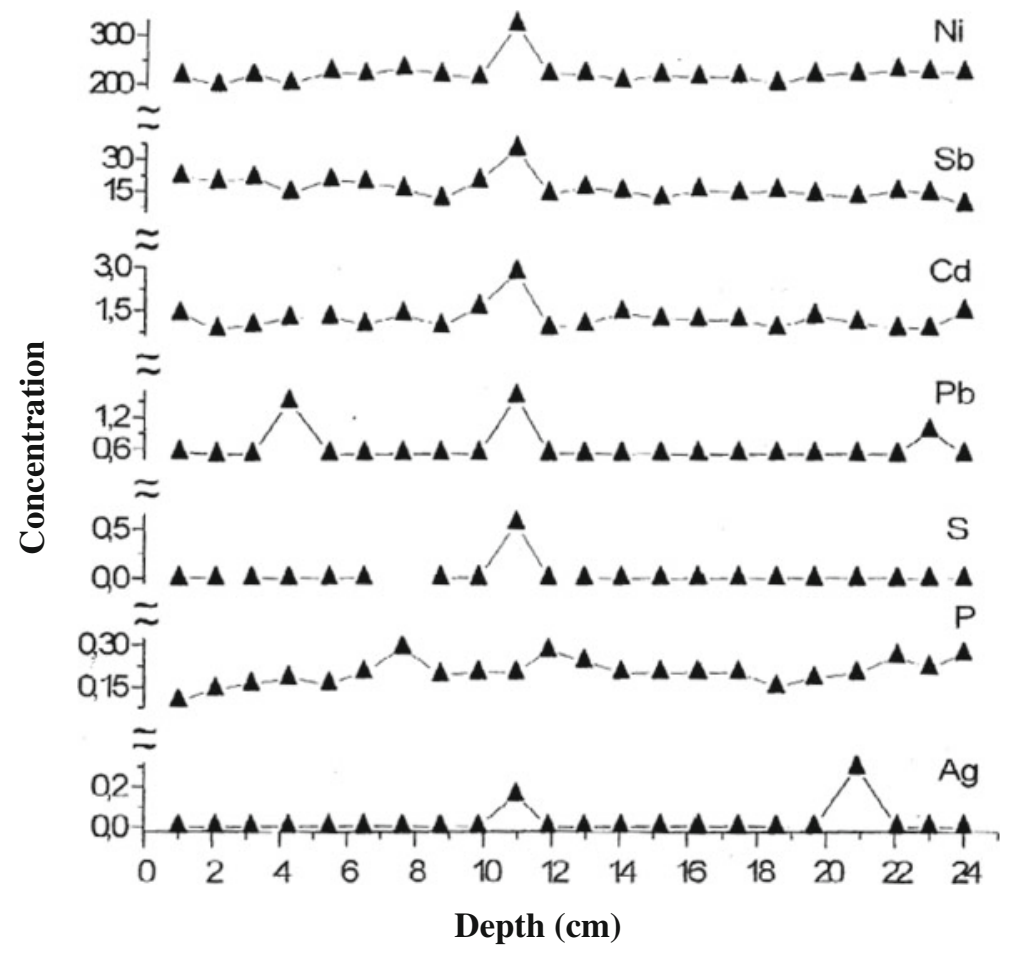

Fig. 3 Trace element distributions in the sediment cores from southern Turkey 

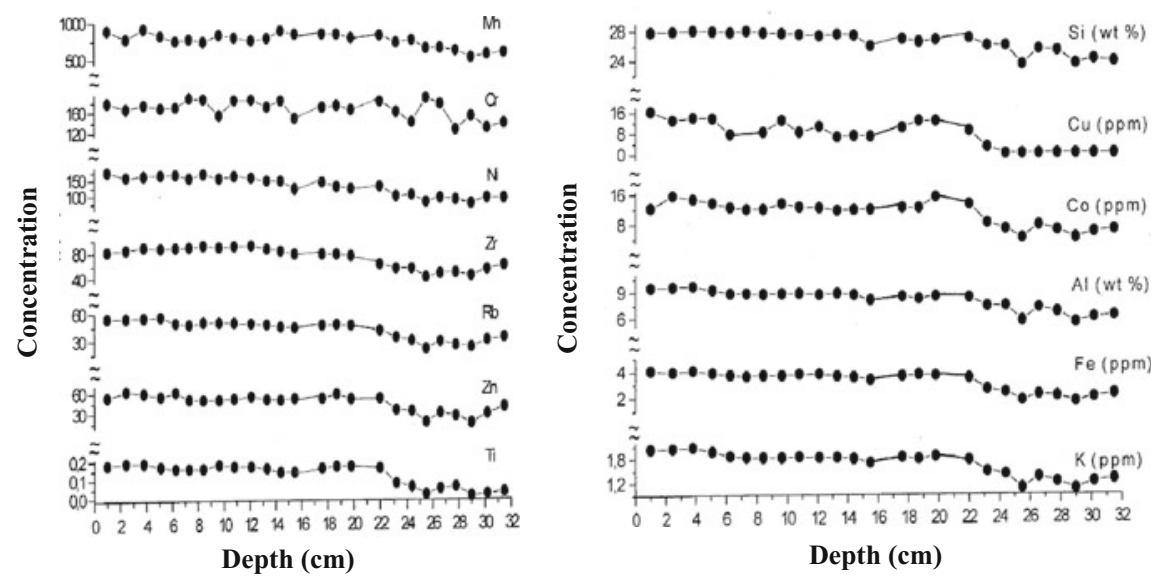

Fig. 4 Trace element distributions in the sediment cores from North Cyprus

A steady increase in elemental concentrations is observed at $24 \mathrm{~cm}$ depth corresponding to about 80 years and continue until the surface. Cyprus in known to be have rich reserves of copper mines. After 1974 the mining companies stoped their activities. As a result the region become a serious environmental disaster area. The mining activities as well as the remains of the copper mine works may be the primary sources of elemental pollution observed.

\section{References}

1. Goldberg ED (1963) Radioactive Dating. IAEA STI/PUB/68, Vienna, Austria, p 121

2. Krishnaswami S, Lal D, Martin JM, Meybeck M (1971) Geochronology of lake sediments. Earth Planet Sci Let 11:407-414

3. Robbins JA, Edgington D (1975) Determination of recent sedimetation rates in lake Michigan using Pb-10 and Cs-137. Geochim Cosmochim Acta 39:285-304

4. Smith PP, Valton A (1980) Sediment accumulation rates and geochronologies measured in the Saguenay Fjord using the Pb-210 method. Geochim Acta 44:225-240

5. Erten HN, von Gunten HR, Rössler E, Sturm M, Schweiz Z (1985) Dating sediments from lake Zurich (Switzerland) with ${ }^{210} \mathrm{~Pb}$ and ${ }^{137} \mathrm{Cs}$. Schweiz Z. Hydrol 47:5-11

6. von Gunten HR, Sturm M, Erten HN, Rössler E, Wegmüller F (1987) Sedimentation rates in the central lake Constance determined with ${ }^{210} \mathrm{~Pb}$ and ${ }^{137} \mathrm{Cs}$. Schweiz Z Hydrol 49:275-283

7. Evans G, Erten HN, Alavi SA, von Gunten HR, Ergin M (1989) Superficial deep-water sediments of the Eastern Marmara basin. Geo-Marine Lett 9:27-36

8. Tadjiki S, Erten HN (1994) Radiochronology of sediments from Mediterranean sea using natural ${ }^{210} \mathrm{~Pb}$ and ${ }^{137} \mathrm{Cs}$. J Radionanal Nucl Chem 181:447-459

9. Gökmen A, Yıldız M, Erten HH, Salihoğlu I (1996) Dating of sea of Marmara sediments by a uniform mixing model. J Environ Radioactivity 33:91-104

10. Erten HN (1997) Radiochronologies of lake sediments. Pure Appl Chem 69(1):71-76

11. Ayçık GA, Çetaku D, Erten HN, Salihlioğlu I (2004) Dating of Black sea sediments from Romanian coast using natural Pb-210 and fallout Cs-137. J Radioanal Nucl Chem 259:177180

12. von Gunten HR, Sturm M, Moser RN (1997) 200-year record of metals in lake sediments, their history, influence factors, regional differences. Environ Int. 31:63-75 